\title{
Persistent threats need persistent counteraction: responding to PCB pollution in marine mammals
}

\author{
Sarah Stuart-Smith, Paul D. Jepson*
}

*Corresponding author

Keywords: Polychlorinated biphenyls; PCBs; Stockholm Convention; cetacean; Europe; pollution

\begin{abstract}
Polychlorinated biphenyls (PCBs) are a type of persistent organic pollutant (POP) that continues to pose a significant environmental threat to humans and wildlife. Recent scientific evidence shows that very high PCB concentrations are still major causes of contemporary declines in European cetacean populations, and potentially other marine apex predators globally. Currently, controls on PCBs are insufficient, on their own, to fully protect human health or to conserve wildlife. Although the Stockholm Convention provides a global framework to address PCBs, there appears to be a systemic shortfall of many parties of the Convention to provide sufficient prioritisation and resources for effective implementation. A 2015 United Nations Environment Programme assessment estimates that the vast majority of PCB-contaminated equipment and materials, around 14 million tonnes, still requires elimination. At present rates of PCB elimination or mitigation, many countries, including some European countries, will not achieve the 2025 and 2028 targets of the Stockholm Convention. It is imperative that the Conference of the Parties for the Stockholm Convention conclude article 17 negotiations on a compliance mechanism for the Convention as soon as possible. To help mobilise global efforts towards eliminating the threat from PCBs, an enforceable, effective and robust compliance mechanism should be established, along with capacity building support for developing countries. In Europe, renewed action is needed to reduce PCB contamination, in order to prevent some killer whale (Orcinus orca) and other dolphin populations from continuing to slowly decline, potentially towards extinction.
\end{abstract}

\section{Introduction}

The threats to human health and the environment from polychlorinated biphenyls (PCBs) have long been understood and well evidenced (EC 2014). PCBs are carcinogenic and mutagenic persistent 
organic pollutants (POPs) that bio-accumulate up the food chain, with greater impacts on species at higher trophic levels such as apex predators (EC 2014). In response to the severe, deleterious impacts from PCBs, regional prohibitions on PCB production initiated in the late 1970s (Yoder 2003), cumulating in global prohibition initiatives on production and use through the 2004 entry into force of the Stockholm Convention, which currently has 180 parties (http://chm.pops.int/default.aspx). Although Europe has been considered a 'world leader' in addressing the risk from PCBs (UNEP 2015a), recent research on cetaceans suggests that further action is required to mitigate the legacy PCB material and contamination still present within Europe (Jepson et al. 2016: Jepson and Law 2016; Law and Jepson 2017). Cetacean blubber PCB concentrations initially declined following the mid-1980s European (EU) ban on PCB use and manufacture, but have since stabilised in most European biota (including cetaceans) with PCB levels in multiple dolphin species markedly exceeding all known marine mammal PCB toxicity thresholds. Population declines in these species are likely the result of lack of recruitment from reproductive failure, which is consistent with the observed high PCB concentrations in adult females (Jepson et al. 2016). The few remaining coastal killer whale (Orcinus orca) populations are close to extinction in the most industrialised regions of Europe (Jepson et al. 2016: Jepson and Law 2016). Some locations in Europe, such as the western Mediterranean Sea and South-west Iberian Peninsula are global PCB 'hotspots' for marine mammals, but all regions of Europe have high PCBs compared to non-European countries (Jepson et al. 2016). This raises the question whether such hotspots occur because they are located near contaminant outlets to the marine environment? Or whether through PCB movement in the marine environment they have inadvertently become highly concentrated sinks?

PCBs can be transported significant distances beyond their sources and to regions where there was no history of PCB production or use - such as the Arctic (EC 2007). Very high PCB concentrations and other POPs were found in two endemic amphipods (Hirondellea dubia and Bathycallisoma schellenbergi) over 10,000 metres depth at the bottom of the world's deepest oceanic trench (the Mariana Trench) in the Pacific Ocean (Jamieson et al 2017). The killer whale remains the most highly PCB-contaminated mammalian species on earth, due to their high trophic level, their longevity and the very high maternal transfer of PCBs through their fat-rich milk (Jepson and Law 2016). Historically, the killer whale had a global distribution, but large killer whale populations are increasingly found only in the less industrialised (and less PCB-polluted) Antarctic and Arctic regions. Other marine apex predators, such as some shark species or polar bears (Ursus maritimus), may also be at significant PCB risk. Many marine shark species have been declining worldwide in the last 30 years or so, but there has been insufficient research in most shark species to assess thoroughly if there have been any population level impacts from PCBs (Jepson and Law 2016). 
This paper assesses the current weaknesses in the global and regional policy framework to address PCBs, assesses barriers to the effective implementation of the Stockholm Convention, and identifies actions that need to be taken urgently if the impacts of PCBs on cetaceans and other species are to be mitigated effectively.

\section{There is already a global framework to address PCBs, why is further action needed?}

The Stockholm Convention was developed to address POPs, including PCBs. The primary aims of the Convention with respect to PCBs are that it seeks the elimination of PCBs through prohibiting their production and use (Stockholm Convention, art 3 (1)(a)(i)). Parties are working towards a target to eliminate use of PCB equipment by 2025 and to have environmentally sound waste management for PCB liquids and contaminated PCB equipment (above 0.005\% PCB content) by 2028 (Stockholm Convention, Annex A, Part II (a), (e)). After the prohibition on PCB use and manufacture in the US (1979), UK (1981) and the EU (1987) and subsequent global implementation of the Stockholm Convention after it entered into force in 2004, PCBs levels in all biota and environmental matrices started to fall - in all regions (Jepson and Law 2016; Jepson et al. 2016). At this point in history, many scientists and policy makers may have been forgiven for thinking that the PCB problem was effectively solved and that PCB levels would continue to decline sharply for many years to come. However, the very high and stable PCBs concentrations in European biota today show very clearly that current European initiatives to eliminate PCBs are insufficient to conserve killer whales and other European wildlife (Jepson and Law 2016; Jepson et al. 2016; Law and Jepson 2017).

Vast quantities of PCB are still contained in stockpiles, contaminated equipment and materials stored in landfills or in active use (DEFRA 2013). PCBs were used as heat transfer fluids and electrical equipment, such as transformers and capacitors, compromise the largest proportion of known PCB equipment and materials requiring elimination (DEFRA 2013; UNEP 2007; UNEP 2015a). They also had wide usage in other specialised equipment and materials, such as hydraulic fluid, solvents, sealants, and oils (UNEP 2007). Most PCB emissions into the environment have come from leaks of di-electric fluids used in electrical equipment (DEFRA 2013). Although there have been active efforts by Stockholm Convention parties to reduce 'closed applications' of PCBs, such as transformers and capacitors, there is a growing contemporary threat from 'open applications' of PCBs, in materials such as solvents and sealants, which is frequently overlooked in implementation efforts by parties (Kohler et al. 2005). 
The 'open applications' of PCB are often are still in widespread use and are frequently contained in old buildings (Kohler et al. 2005; Weber et al. 2011). For example, many buildings constructed between 1950 and 1980 possess joint sealants with PCBs and are often unaccounted for in national PCB inventories even though they represent a considerable PCB stockpile (Kohler et al. 2005). Former paints for bridges and ships also frequently contained PCBs (and PCNs), and areas where ships have been painted and repainted can be contaminated and become long term hotspots for POPs, including PCBs (as well as other contaminants such as PCNs, DDT, tributyltin and heavy metals) (Eklund \& Eklund 2014; Johnsen \& Engoy 1999). Furthermore, abrasive blasting of bridge paint can release considerable amounts of PCBs into the environment, for example at least $100 \mathrm{~kg}$ of PCBs was released from abrasive blasting paint removal of a bridge in the Czech Republic that contaminated the Elbe River and increased PCB concentrations in sediment (ELSA 2016). In addition, the abrasive blasting of a painted concrete bridge in Norway released approximately $1600 \mathrm{~kg}$ of PCBs and increased PCB contamination in the local environment (Jartun et al. 2009).

The significance of 'open applications' as a major contemporary source of PCBs should not be underestimated as 'open applications' are believed to be responsible for most PCB releases into the environment and subsequent contamination of consumables today (Weber et al. 2015b). A recent study on PCB in the environment and related impact on food in Germany has estimated that from the 25,000 tonnes of PCB in 'open applications', still 50-80 \% may still be present, and at least $7-12$ tonnes of PCBs are released into the environment from them (Knetsch et al.2014; Weber et al. 2015b). In Switzerland, another study estimated 1 tonne PCBs being released from 'open applications' (Diefenbacher et al. 2015). Both studies suggest that the PCB release from 'open applications' is an order of magnitude higher than the reported PCB release from these countries for the Convention on Long-Range Transboundary Air Pollution, United Nations Economic Commission for Europe and Aarhus Protocol on Persistent Organic Pollutants. In addition, although buildings can have annual PCB emissions of more than 100g they are also not included in European Pollutant Release and Transfer Register (Weber et al. 2015b). The potential volume of 'open application' PCB stockpiles is even greater when there is consideration that as these 'open application' materials reach end of life and are disposed of, they often pass into municipal solid waste and landfills build up significant quantities of PCB contaminated material that is not necessarily appropriately handled. Furthermore, landfills also frequently contain PCB waste from electrical equipment deposited in the 1970s and 1980s (Weber et al. 2011).

Few countries have made any effort to identify 'open application' sources of PCBs and only Sweden has an inventory of 'open application' PCBs in buildings. Other European countries do not have 
detailed inventories of 'open application' PCBs and do not adequately manage for this source of PCBs. The insufficient European efforts to address 'open application' PCB sources is in part due to shortfalls of the Stockholm Convention for these PCB sources and the PCB Directive (Council Directive 96/59/EC) which does not address 'open applications' despite their high relevance and widespread former use across Europe (EC 2014; Knetsch et al. 2014; Weber et al. 2015b).

Under the Stockholm Convention parties are required to develop National Implementation Plans, to take appropriate measures for addressing the PCB-containing equipment and waste legacy by undertaking environmentally sound management or destruction of PCB stockpiles and wastes (Stockholm Convention, art 6). The first ten year assessment of the implementation of the Stockholm Convention for PCBs, however, suggests that without rapid change to state practice, neither the 2025 or 2028 targets will be met (UNEP 2015a). The 2015 United Nations Environment Programme (UNEP) assessment estimated that the vast majority of PCB (containing or contaminated with) equipment and materials, around 14 million tonnes, still required elimination, and the global efforts to date had only eliminated 1.6-3.1 million tonnes of PCB equipment and materials (SCB 2016). This finding is even more alarming as PCBs contained in landfills - major sources of PCBs leaching into rivers and estuaries - were not considered in this assessment (UNEP 2015a). Despite the high levels of PCB equipment and materials remaining, there has been a decline in elimination efforts by parties since 2007. This decline may reflect that the easily accessible targets for elimination have been dealt with, creating slower progress to address less accessible waste. Alternatively, it may reflect a reduction in resourcing due to the global financial crisis coupled with increased perception that the PCB threat is under control (UNEP 2015a).

There are regional differences in elimination progress, for example UNEP has reported that a significant proportion of remaining PCB equipment and materials is in developing countries (UNEP 2015a; 2015b). This is largely due to these countries possessing insufficient facilities for PCB destruction and limited access to appropriate destruction technology (Weber et al. 2013; 2015). Municipal waste landfills containing PCBs are also often inappropriately managed, or open-burned in developing countries (Weber et al. 2011). It is also unclear to what extent 'open applications' of PCBs were used in developing countries and improvements in managing these sources of PCBs are likely to also be required.

Despite reporting of high volumes of PCB equipment and materials remaining in developing countries, the vast majority of the PCBs used historically were in the industrialised regions of North America and Europe, mainly involving large quantities of PCB waste and on-going sources of 'open 
application' PCBs in old materials, which still persists (Weber et al. 2013). In fact, there is evidence that developed countries in Europe particularly, also have a shortfall in effective implementation of the Stockholm Convention (IEEP 2014). The most recent fitness check of the PCB Directive suggested that the majority of EU Member States had failed to achieve the 2010 elimination target of the Directive and concluded that there was a 'persistent lack of implementation in member states' (EC 2014). Although the PCB Directive holds member states to a higher standard than the targets required in the Stockholm Convention, the fitness check revealed the insufficient progress towards eliminating PCBs in Europe and lack of political will from member states. In particular, significant quantities of transformers and other 'closed application' PCB equipment and materials are contained in France and Spain (CLEEN 2005). It can therefore be inferred that without rapid acceleration of elimination efforts, many European countries will not meet the 2025 and 2028 targets of the Stockholm Convention.

Furthermore, many countries practice containment as an alternative to destruction of POP wastes and do not always successfully manage POPs in an environmentally sound manner (Weber et al. 2013). For example, a 2011 investigation into a German company involved in PCB management discovered that staff working at the factory had elevated blood PCB levels due to inadequate controls and insufficient mitigation measures at the site (Weber et al. 2015a). Containment facilities and PCB equipment and materials in landfills pose greater environmental risks than small amounts of low concentration PCB equipment and materials distributed over a wider area owing to the collective higher PCB concentration and its potential for entering into the environment (UNEP 2007). Some experts have noted that even landfills equipped with the 'best technology' to handle PCBs still pose a significant risk as over time as containment systems can eventually degrade and lose structural integrity, thus enhancing the risk of PCBs leaching or volatising into the environment. PCBs can still remain highly toxic owing to the extremely long timeframe for their natural degradation (Weber et al. 2011). There are also examples of 'best technology' landfills equipped to handle hazardous waste in Europe nonetheless leaching POPs (including PCBs) into waterways as a result from flooding during heavy rains (Weber et al. 2011). In light of this risk posed by concentrating PCB equipment and materials in particular locations, destruction facilities should have sufficient capacity to ensure that their collection depots do not become de-facto storage facilities (UNEP 2007). This is a risk that is potentially greater in Europe as number of European countries contain industries specialised in the destruction or decontamination of PCB equipment and receive PCB imports from other countries, including developing countries as well as other European nations (IEEP 2014). 
Another legacy PCB reservoir that contributes to long-term release of PCBs into the environment is the PCBs that were used in mines as hydraulic oils during the 1960s-1980s. PCBs are released from the mines into the environment through leaching, and when ground water from mines is pumped into surface water. In Germany up to 12,000 tonnes of PCBs have been used as hydraulic oils in mines (Detzel et al. 1998). Ground water pumping from mines has generated PCB contamination levels as high as $1400 \mu \mathrm{g} / \mathrm{l}$, which is above European environmental quality standards (Der Spiegel 2015a). Fish in rivers contaminated from these sources have been recorded with high PCB levels (IKMS Internationale Kommission zum Schutz der Mosel und der Saar 2005). The risk from increased PCB environmental contamination and drinking water has been raised by the Green Party and by the civil society organisation BUND (Der Spiegel 2015b). The detected release of PCB above environmental standards might require a remediation of the mines or a cleaning of the pumped waste water (Dohmen and Schmid 2015).

There is clear need for additional research and monitoring to assess the global PCB waste legacy and the extent of on-going pollution from it into the environment. Certainly within Europe, there is evidence that PCBs are still entering the environment. For example, OSPAR has recorded that PCB releases into water do continue in the region, although further research is required to assess the extent of it (OSPAR 2010). Based on the vast quantities of PCBs requiring elimination as reported by UNEP, as well as the risk of leaching or volatising into the environment that stockpiles and landfills pose, it is reasonable to conclude that there are major on-going sources of PCB pollution still entering into the environment. Clearly, the very high and stabilised levels of PCBs detected in European biota further reflect that there is on-going PCB pollution entering the environment. Even if the pollution levels from individual sources are low, the cumulative impact is high - particularly at the very top of the marine food chain (Jepson et al 2016; Jepson and Law 2016).

For marine species, the impact from PCBs already in the marine environment is significant as PCBs contained in sediment are regularly mobilised from human activities, such as dredging, bottom trawling and construction, as well as natural events such as tidal surges and extreme weather events (Roberts 2012; Eggleton and Thomas 2004). Sediment often acts as a reservoir for pollutants such as PCBs that can easily be mobilised from the sediment during a disturbance owing to their chemical properties (Nicolaus et al. 2015). Studies show that PCBs released from sediment during a disturbance such as dredging or bottom trawling, can remain mobile for many months after the disturbance and can be detectable at considerable distances away from the disturbance site. Mobilised PCBs pose a much greater risk as they can enter the food chain by being absorbed or consumed inadvertently microorganisms and then subsequently pass on to other organisms such as filter feeders and fish, bio- 
accumulating up the food chain (Eggleton and Thomas 2004). Despite the risk of PCB mobilisation from disturbance events, the risks from increased PCB contamination due to human activities, such as dredging, can be reduced where the correct risk management and environmental protocols are adhered (Roberts 2012). That said, management of PCB-contaminated sediment requires improvement in order to effectively eliminate this source, for example more could be achieved in Europe through enhancing the Water Framework Directive (Council Directive 2000/60/EC) (Förstner et al. 2015).

Sediment reservoirs pose a persistent PCB sink, for example, the Hudson River in the US is estimated to have $20-440$ tonnes of PCBs (with a most probably range of 150 - 200 tonnes) (Mackler 2000), which is in the same volume range as the former PCB release from General Electric into the Hudson River (Limburg et al. 1984; EPA 2016b). In addition to disturbance events, sediment POP reservoirs in rivers also continually release POPs into the sea through the natural movements of river water. In the Kymyoki River after over 35 years since the closure of a PCP production source, the $30 \mathrm{~kg}$ TEQ total release into the river has changed to: $4.5 \mathrm{~kg}$ in sediment at the product site, $12 \mathrm{~kg}$ in sediment along the river bed and $12 \mathrm{~kg}$ reached the Baltic Sea by 2009 (Verta et al. 2009). Contemporary activities such as abrasive blasting of PCB containing bridge-paints also contribute to river sediment PCB reservoirs (Jartun et al. 2009; ELSA 2016). It also is uncertain how extreme weather events may influence PCB mobilisation from contaminated sediments (Roberts 2012).

\section{Barriers to effective implementation of the Stockholm Convention}

Overall, there appears to be a systemic shortfall for most contracting parties to provide sufficient resources and prioritisation for the effective implementation of the Stockholm Convention (UNEP 2015a; Weber et al. 2015a). This underperformance is not just restricted to efforts to eliminate PCBs - many contracting parties appear ambivalent about other obligations under the Convention as well. Only $40 \%$ of parties, for example, submit their national reports to the Convention (UNEP 2015a). For the Stockholm Convention to fulfil its PCB aims and for parties to effectively implement the Convention, issues relating to limited PCB inventories, resourcing for PCB decontamination and political support will need to be overcome.

\subsection{Limited information on PCB equipment and materials}

The largest challenge that the global community faces with addressing PCBs is that the extent of PCB equipment and materials is not known; governments do not have sufficient information to assess this accurately (IEEP 2014; UNEP 2015a). This is because PCB equipment and materials are not a simple correlation with the amount of PCB produced originally as the impacts of dilution, contamination, 
recycling and use in equipment has meant that the legacy is significantly larger the 1-2 million tonnes of PCBs produced in the $20^{\text {th }}$ century (UNEP 2015a). For example, recycling practices where transformers that previously used PCBs are retrofitted with substitutes such as mineral oil create additional PCB contaminated oil, albeit at lower concentrations, in addition to the contaminated equipment and original PCB liquid (IFCS 2001; UNEP 2015a). Furthermore, even original PCB containing equipment and materials can be difficult to identify as many of these products were not labelled according to whether PCBs were present or not (UNEP 2007). It is possible to make inferences for some items based on time and location of manufacture, for example there is a high likelihood of PCBs in electrical equipment if it was manufactured prior to1980 in Europe (CLEEN 2005). However, for 'open applications' such as paints, solvents oils and sealants, it impossible to assess the exact quantity of PCB contaminated materials owing to the untraceable and frequently disposable use of such materials (UNEP 2007; Jartun et al. 2009). That said, there have been efforts in Sweden (for buildings) and Germany to compile information on quantities of PCBs in former 'open applications', which is a valuable effort given the significance of this source of PCBs for releases into the environment (Knetsch et al. 2014; Weber et al. 2015b).

The challenges of creating an accurate inventory of PCB equipment and materials are further confounded by the fact that many PCB equipment and materials are privately owned and there is lack of awareness on identifying them and handling the items appropriately (IEEP 2014). Some members of the Polychlorinated Biphenyls Elimination Network (PEN) have noted that despite significant resources being dedicated to developing national inventories, the information frequently remains unreliable and inadequate (UNEP 2015b).

\subsection{Resourcing PCB mitigation}

Effective destruction facilities and environmentally sound management of PCBs is financially costly. For parties that do not have destruction facilities, such as many developing countries, costs can be very high. These countries will frequently export some of their PCB waste, following requirements of the Stockholm and Basel Conventions, to another country with the appropriate waste management facilities (IEEP 2014). The resourcing challenges for developing countries are widely recognised and there have been efforts through the Global Environment Facility (GEF) to provide support such as inventory projects and capacity building (UNEP 2015b). However, this support has not been enough and the 2015 UNEP assessment highlights the significant volume of PCB equipment and materials remaining in developing countries (UNEP 2015a). Even within industrialised regions, there can be insufficient capacity to address PCB waste from the region itself, as there has not been adequate investment in the necessary infrastructure. For example, a 2005 report on PCB elimination in Europe 
suggested that although there was capacity to incinerate all PCB liquid waste by 2010 , there was insufficient capacity to treat and clean equipment, such as transformers, and stockpiles of such contaminated equipment would likely persist for at least a decade before being handled (CLEEN 2005). In responding to the findings of the recent $P C B$ Directive fitness check, European member states suggested that their elimination shortfalls were due to resource-related constraints such as lack of destruction facilities, economic barriers and the European and global financial crises (IEEP 2014).

\subsection{Political appetite}

There is wide recognition in the global community, reflected by the high membership of the Stockholm Convention, of the threat of PCBs and the need for their management. However, the political appetite to continually undertake the necessarily actions to eliminate or provide effective environmentally sound management of PCBs is not reflected in investment and resource allocation, particularly in Europe (Weber et al. 2015a). There are perceptions that the early declines in PCB levels in biota and the environment indicate that PCB regulations have been a success and the threat is largely under control and remaining emissions are minor (DEFRA 2013; Weber et al. 2013). Some members of the PEN have expressed views which minimise the concerning conclusions of the 2015 UNEP assessment by suggesting that there was insufficient information to draw any conclusions and that focus needed to be placed on improved reporting and data (UNEP 2015b). Other views indicate that many consider the PCB legacy to be sufficiently addressed in developed countries and the remaining efforts are burden of developing countries with future efforts to be focused on capacity building and technology transfer (UNEP 2015b). One report on the PCB Directive fitness check suggested that the decreased rate of PCB decontamination in Europe simply reflected that there was less PCB to handle (IEEP 2014), which is in stark contrast to the conclusions of the fitness check itself and an earlier European assessment that indicated that reduced elimination efforts reflected limitations from lack of capacity and inadequate implementation efforts by European member states (CLEEN 2005).

Undoubtedly global efforts to address PCBs have already had some positive impacts, but it is reasonable to infer that there is still on-going PCB pollution entering the environment. Further research is required to assess the level and sources of that PCB pollution. Addressing PCBs remains a global concern for both developing and developed countries alike. It is recognised that additional capacity building and support to developing countries will be essential to help achieve the 2025 and 2028 targets of the Stockholm Convention (Weber et al. 2013). 


\section{Further actions required to reduce the current PCB threat}

It is reasonable to conclude that the current global implementation efforts for the Stockholm Convention have not been sufficient and parties need to be incentivised to provide the political appetite and resourcing to address the world's PCB legacy. Initiatives to address PCBs need to be global in nature, as well as include proactive efforts by individual nations. In Europe, current PCB mitigation does not appear sufficient to reduce the contemporary PCB threat to cetaceans.

\subsection{Enhancing the Stockholm Convention}

The framework provided by the Stockholm Convention provides clear targets and requirements for parties to develop National Implementation Plans and to undertake efforts to implement the plan (UNEP 2015a). Complementing the commitments of the Stockholm Convention, numerous international forums exist to provide guidance, information exchange and partnership with industry and other stakeholders to help eliminate and undertake environmentally sound management of PCBs. These include the PEN, the International Conference on Chemicals Management and various fora through UNEP to implement the Strategic Approach to International Chemicals Management (SAICM) (UNGA 2012; UNEP 2015b). The activities of these fora are valuable and help enable the global community to address PCBs; however, their efforts should not be viewed as a substitute for ensuring compliance under the Stockholm Convention. The poor record from first ten years of implementing the Convention indicates that these 'soft law' or voluntary guidance based approaches have not been effective on their own for incentivising parties to effectively fulfil their obligations under the Stockholm Convention.

As the treaty currently stands, it provides an inefficient framework for compliance and enforcement (Yoder 2003). However, Article 17 of the Convention provides that procedures and institutional mechanisms for compliance and enforcement will be developed by the Conference of the Parties (CoP). Since 2006 an ad-hoc open-ended working group has been negotiating and developing draft options for a compliance mechanism. These options have been actively discussed at CoPs in 2009, 2013, 2015 and 2017 and negotiations remain deadlocked on a number of key issues, such as the inclusion of a non-party (or Secretariat) trigger for compliance submissions. With a view to resolving the negotiations, parties were asked to undertake intercessional work in 2016 on the proposed option to facilitate discussions at the $2017 \mathrm{CoP}$. The 2016 intercessional views submitted by parties and the unsuccessful negotiations at the $2017 \mathrm{CoP}$ demonstrated the on-going divided views and tension between developing and developed countries (http://chm.pops.int/TheConvention/Compliance/tabid/61/Default.aspx). 
It is in the authors' opinion, that to ensure effective implementation of the Stockholm Convention, there needs to be a commitment by parties to complete Article 17 negotiations expeditiously and to rapidly establish an operational compliance and enforcement mechanism. This mechanism should include the following features:

- Scope to rigorously assess compliance across all obligations under the Convention

- A non-party trigger, either by the Secretariat or Committee, for submissions

- A civil society notice procedure to bring attention compliance issues to the non-party trigger body (Secretariat or Committee) for the body make inquiries where necessary

- Where appropriate, the Committee should have the option to seek funds from the GEF or an implementation fund to provide compliance assistance prior to making a determination on noncompliance

- The Committee to have a majority-vote instead of consensus decision making

- The CoP should be empowered to take actions, such as financial penalties or remediation assistance, where non-compliance is determined by the Committee.

All features listed above are based on precedents established in other multilateral environmental agreements (e.g. Montreal Protocol; World Heritage Convention). These features have been selected to ensure that the compliance mechanism has the ability to incentivise both developed and developing countries to implement their obligations under the Convention, recognising that elimination of PCBs still requires a global effort. Through providing enhanced international accountability on compliance with the Stockholm Convention, political appetite and prioritisation of resources may be improved to allow for more effective national implementation activities.

In addition, the first evaluation cycle of the Convention to be submitted at the ninth CoP is an opportunity for parties to assess whether the 2028 target to have environmentally sound waste management for PCB liquids and contaminated PCB equipment (above $0.005 \%$ PCB content) is too weak in light of the risks posed by even the best practice landfills and storage facilities. Arguably, the Convention needs to be strengthened significantly to recognise that destruction or irreversible transformation is the only long term solution to dealing with the world's PCB legacy, even for low concentration contaminated items (Weber et al. 2015a). Furthermore, the Convention should also be strengthened to more effectively address 'open applications' of PCBs. The $2017 \mathrm{CoP}$ made a valuable step forward in this respect through encouraging parties to identify 'open applications' containing more than $0.005 \%$ PCBs and to manage them in accordance with the Convention's rules on stockpiles (http://enb.iisd.org/chemical/cops/2017/). 


\subsection{National implementation activities}

As there is reasonable probability that $\mathrm{PCBs}$ are still entering the environment from sources such as landfills, 'open applications' and stockpiles, national implementation activities need to focus on eliminating all PCB equipment and materials. To reduce the risk of PCBs entering the environment it is important that parties prioritise elimination efforts, adopt a more precautionary approach to waste management generally, and undertake efforts to improve education and awareness of PCB equipment and materials.

Despite the poor implementation by states exposed in the fitness check of Europe's PCB Directive, the assessment did acknowledge that there was a robust framework provided by the legislation and waste management policies across Europe (EC 2014). However, five European states (Austria, Netherlands, Belgium, Norway and Sweden) have stricter regulations for PCB management than the $P C B$ Directive suggesting that they consider that measures in the Directive are insufficient (IEEP 2014). Other states have indicated that they view the current $P C B$ Directive measures as appropriate and commentators have noted that setting stricter measures would increase the financial burden and hinder implementation progress (IEEP 2014). Other commentators have noted that in general the European legislative standard for environmentally sound management and elimination of PCBs provides a 'gold standard' that should be adopted elsewhere (UNEP 2015b; IEEP 2014). However, legislative frameworks can only be effective if there is sufficient resourcing and political will to implement them fully. In addition, although the PCB Directive provides a robust framework to address 'closed applications', it and the associated European waste management policies, are not adequate to comprehensively address 'open applications' - despite these being major contemporary sources of PCBs (Weber et al. 2015a).

Noting the persistence and threats to human health and the environment that PCBs pose, destruction or irreversible transformation is the only long term solution to dealing with the world's PCB legacy regardless of the costs involved (Weber et al. 2015a). Furthermore, given the high toxicity of PCBs, the benefits from disposing PCBs through total destruction should be considered to outweigh the costs involved (IEEP 2014). The importance of prioritising elimination activities is even greater when the risk of PCBs leaking into the environment from storage facilities and landfills is taken into account (Weber et al. 2011). Leakages to the environment from storage and landfill sites can be minimised by enhanced monitoring, compliance and auditing by competent authorities (Weber et al. 2011; 2015). However, costs of on-going monitoring can be high owing to the personnel costs involved (EC 2014). Despite the expenses involved for PCB destruction, in the long term it is likely to be cheaper to 
destroy PCB equipment and materials rather than maintaining on-going regimes of handling and storage of these materials with their associated monitoring and audit costs (Weber et al. 2011; 2015). Investment in destruction infrastructure can have wider benefits than simply enhancing PCB elimination efforts as these facilities are usually general incineration facilities that handle other hazardous waste as well (EC 2014).

GEF support for the management of PCBs is currently inadequate to provide sufficient support to developing countries to implement the Convention effectively, especially noting that many developing countries lack destruction facilities and export their POPs for destruction (UNEP 2015b). The GEF-6 programme for 2014-2018 allocates a target of \$375 million for POPs resourcing (GEF 2014). However, the export of POP-contaminated materials for destruction has been estimated to cost between US $\$ 2,000$ to US US $\$ 5,000 /$ tonne. The GEF would need US $\$ 28$ billion and US $\$ 70$ billion to export the estimated 14 million tonnes of PCB contaminated equipment and materials that still require elimination (Weber et al 2013; UNEP 2015a; SCB 2016). However, the actual costs are even higher noting that UNEP's estimates of remaining PCB contaminated equipment and materials exclude 'open applications' and landfill sources of PCBs (UNEP 2015a). Significant additional financial support for developing countries is essential to improve global implementation of the Convention.

Although the US is a non-party to the Stockholm Convention, it adopts a novel approach to disposing of PCBs through assessing risk areas under a Hazard Ranking System (HRS) and designating 'Superfund' sites for prioritisation of remediation of chemical pollutants such as PCBs or other hazardous materials (EPA 2016). This strategic approach to the identification and decontamination of pollution 'hotspots' has been associated with long-term declines in PCB levels in US biota/humans that still continue today (Xue et al. 2016). Implementation of the Stockholm Convention by parties could be enhanced through adopting innovative approaches that draw on the stricter controls of the European legislative framework, but also enabling countries to strategically identify high risk stockpiles and landfills for priority destruction or irreversible transformation.

Although there are frequent global calls to improve national inventories and obtain more information on PCB equipment and materials, efforts to fund and enhance our understanding should not be at the expense of progressing on-going efforts to eliminate PCBs (UNEP 2015a; 2015b). The challenges associated with developing national inventories and obtaining knowledge on the location and quantities of all PCB equipment and materials are so vast it likely that they will never be fully overcome in both developed and developing countries (UNEP 2007). As such, parties should adopt even greater precautionary approaches such as destroying PCB materials at lower threshold 
concentrations and managing any potential 'open application' sources such as materials from old buildings as though they are contaminated with PCBs (Weber et al. 2015a; Kohler et al. 2005). In Europe, there are already some regulations, such as those under Council Directive 2011/65/EU, on the disposal of certain PCB 'open applications', however, this is often unenforced and reliant on the ability of the private sector to identify, collect and dispose of PCB contaminated material (EC 2014).

Increasingly, governments are considering extended producer responsibility policy options that encourage companies involved in the contemporary production of hazardous substances to retain some responsibility (financial or physical) for post-consumer disposal or treatment (OECD 2001). Civil society groups have also been vocal for manufacturers of PCBs, such as Monsanto and Bayer, to retrospectively assume responsibility for the disposal of PCB waste materials produced in the past (e.g. http://globaljusticeecology.org/monsanto-cant-shake-poisonous-history-of-pcb-contamination/). Given the scale of PCBs in both 'open' and 'closed' applications that still require elimination, any extended producer responsibility assumed would be a positive contribution to the effective management and remediation of PCBs contamination in marine and coastal environments.

For effective implementation of national PCB regulations reliant on the actions of the private sector and members of the public, there needs to be increased compliance and enforcement by the competent authorities (EC 2014). In addition, there should be incentives through subsidy schemes for decontamination and tax incentives for industry that participate in training and education on the identification, collection and disposal of PCB equipment and materials. Competent authorities should increase education and awareness raising efforts with end users and relevant industries to ensure that there is a sufficient understanding on how PCB equipment and materials need to be handled and disposed (IEEP 2014). In particular, competent authorities should actively seek to ensure that the advice and guidance produced by authoritative bodies such as PEN is disseminated and readily accessible to industries and end users in their country (SCB 2016). Improved education, information and awareness efforts on PCBs also enhance parties' implementation of obligations under the Stockholm Convention. There also needs to be greater investment in research and monitoring to identify the high-risk sources of PCBs entering the environment and targeting these sources as an elimination priority. This is a key effort towards parties meeting their obligations under the Stockholm Convention. Areas in Europe identified as global PCB 'hotspots' for marine mammals should especially be prioritised for research identifying potential sources for PCBs entering the marine environment around these regions (Jepson et al. 2016). 
Research should also investigate the impact of chlorinated paraffins on marine apex predators. Chlorinated paraffins have substituted PCBs in many applications, including all major 'open applications' and over $90 \%$ of organochlorine contamination in wildlife in areas of China are from chlorinated paraffins (Zhou et al. 2016). In recognition of the threat that short-chained chlorinated paraffins (SCCPs) pose, the 2017 Stockholm Convention CoP added SCCPs to Annex A of the Convention so that this POP may be managed in accordance with the Convention's framework however, the effectiveness of this step is undermined by the many exceptions relating to continued use of SCCPs (http://enb.iisd.org/chemical/cops/2017/).

\section{Conclusions}

PCBs continue to pose a significant threat to the environment and to human health. Given the bioaccumulating nature of PCBs, it is the long-lived species at the top of the food chain that will attain the highest tissue concentrations and suffer the greatest toxic effects. The killer whale remains the most highly PCB-contaminated mammalian species on earth and is likely to suffer on-going population declines and even localised extinctions in industrialised regions - potentially on a global basis. The potential for human health effects by eating highly PCB-contaminated fish, or from atmospheric exposures from PCB-containing joint sealants in some tower blocks is also explicit. The global progress so far to comply with the Stockholm Convention in relation to PCBs has been woeful. Stockholm Convention parties need to be incentivised through the establishment of a robust compliance and enforcement mechanism to provide the political appetite and resourcing to address the world's PCB legacy and improve their implementation of the Convention. To achieve this, national implementation actions by parties need to boost resourcing allocations, prioritise elimination efforts, adopt a more precautionary approach to waste management generally to handle potential 'open applications' of PCBs, and undertake efforts to improve education and awareness of PCB equipment and materials. Finally, additional capacity building and support to developing countries will be essential to help achieve the 2025 and 2028 targets of the Stockholm Convention.

\section{Acknowledgements}

This research did not receive any specific grant from funding agencies in the public, commercial, or not-for-profit sectors. A special thank you to the John Ellerman Foundation's support for Wildlife and Countryside Link's general marine activities. 


\section{References}

Chemical Legislation European Enforcement Network (CLEEN) (2005) 'EuroPCB: inventory PCB enforcement in member states'

Department for Environment, Food and Rural Affairs (DEFRA) (2013), 'National Implementation Plan for the Stockholm Convention on Persistent Organic Pollutants - United Kingdom of Great Britain and Northern Ireland'

Detzel A, Patyk A, Fehrenbach H, Franke et al. (1998) Ermittlung von Emissionen und Minderungsmaßnahmen für persistente organische Schadstoffe in der Bundesrepublik Deutschland. FuE-Vorhaben 36012 008, im Auftrag des Umweltbundesamtes. UBA-Texte 74/98. Berlin

Der Spiegel (2015a) Gift bleibt Gift. Der Kohlekonzern RAG leitet verseuchtes Grubenwasser in die Flüsse. Der Spiegel 7/2015, 11.02.2015

Der Spiegel (2015b) Geplante Bergwerksflutung: Tausende Tonnen Schmieröl bedrohen Saar und Ruhr. Der Spiegel 3/2015, 11.01.2015.

Diefenbacher, P.S., Bogdal, C., Gerecke, A.C., Glüge, J., Schmid, P., Scheringer, M., Hungerbühler, K. (2015) 'Emissions of polychlorinated biphenyls in Switzerland: A combination of long-term measurements and modeling' Environmental Science \& Technology 49: 2199-2206

Dohmen F, Schmid B (2015) Dreckiges Dutzend. Der Spiegel 35/2015, 69

Eggleton, J. and Thomas K.V. (2004) 'A review of factors affecting the release of bioavailability of contaminants during sediment disturbance events’ Environment International 30: 973-980

Eklund B and Eklund D (2014) 'Pleasure Boatyard Soils are Often Highly Contaminated' Environmental Management 53: 930-946

ELSA (2016) PCB in der Elbe - Eigenschaften, Vorkommen und Trends sowie Ursachen und Folgen der erhöhten Freisetzung im Jahr 2015. Behörde für Umwelt und Energie Hamburg, Projekt Schadstoffsanierung Elbsedimente

European Commission (2007) Commission of the European Communities, 'Community Implementation Plan for the Stockholm Convention on Persistent Organic Pollutants'

European Commission (2014) 'Ex-post evaluation of Five Waste Stream Directives', Brussels, 2.7.2014, $\operatorname{SWD}(2014) 209$ final

Förstner U, Hollert H, Brinkmann M, Eichbaum K, Weber R, Salomons W (2016) 'Dioxin in the Elbe river basin: policy and science under the water framework directive 2000-2015 and toward 2021' Environmental Sciences Europe 28(1): 9

Global Environmental Facility (GEF) (2014), GEF Assembly, GEF/A.5/07/Rev.01,May 22, 2014.

Global Justice Ecology Project (17 February 2017) http://globaljusticeecology.org/monsanto-cant-shakepoisonous-history-of-pcb-contamination/

IEEP (2014) Bio-Intelligence Service, Arcadis 'Ex-post evaluation of certain waste stream Directives - Final report', European Commission - DG Environment

IISD Reporting Service (5 May 2017) '2017 Meetings of the Conferences of the Parties to the Basel, Rotterdam and Stockholm Conventions' http://enb.iisd.org/chemical/cops/2017/

IKMS Internationale Kommission zum Schutz der Mosel und der Saar (2005) Internationales Messprogramm „PCB und verwandte Stoffe an Schwebstoffen und in Fischen in Mosel und Saar 2004“; PLEN 8/2005 
Intergovernmental Forum on Chemical Safety (IFCS) (2001), 'Framework for the management of PCBs' (February 2001)

Jamieson, A. J. Malkocs, T., Piertney, S.B., Fujii T. and Zhang, Z. (2017) 'Bioaccumulation of persistent organic pollutants in the deepest ocean fauna' Nature Ecology \& Evolution 1: 0051

Jartun M, Ottesen RT, Steinnes E, Volden T (2009) 'Painted surfaces - Important sources of polychlorinated biphenyls (PCBs) contamination to the urban and marine environment' Environmental Pollution 157: 295-302

Jepson, PD, Deaville R, Barber JL, Aguilar À, Borrell A, Murphy S, Barry J, Brownlow A, Barnett J, Berrow S, Cunningham AA, Davison NJ, ten Doeschate M, Esteban R, Ferreira M, Foote AD, Genov T, Giménez J, Loveridge J, Llavona Á, Martin V, Maxwell DL, Papachlimitzou A, Penrose R, Perkins MW, Smith B, de Stephanis R, Tregenza N, Verborgh P, Fernandez A and Law RJ (2016) PCB pollution continues to impact populations of orcas and other dolphins in European waters. Scientific Reports 6: 18573

Jepson, P.D. and Law R.J. (2016) Persistent pollutants, persistent threats. Science 352: 1389

Johnsen A, Engoy T (1999) 'Contamination from marine paints - a Norwegian perspective' RTO MP 39 Knetsch G, Terytze K, Weber R (2014) 'A PCB inventory and material flow considering production, historic uses, waste management, sinks and sources’ Organohalogen Compounds 76: 596-599

Kohler, M., Tremp, J., Zennegg, M., Seiler, C., Minder-Kohler, S., Beck, M., Lienemann, P., Wegmann, L. and Schmid, P. (2005) 'Joint Sealants: An overlooked diffuse source of Polychlorinated Biphenyls in Buildings' Environmental Science and Technology 39: 1967-1973

Law RJ and Jepson PD (2017) Europe's insufficient pollutant remediation. Science 356, 148.

Limburg KE (1984) 'Environmental impact assessment of the PCB problem: a review' Northeastern Environmental Science 3: 122-136

Mackler MS (2000) 'Estimation of the total PCB mass in the Hudson River system' Master Thesis, Columbia University April 2000

Nicolaus, E., Manuel, E., Law, R.J., Wright, S.R. and Lyons B.P. (2015) 'Spatial and temporal analysis of the risks posed by polycyclic aromatic hydrocarbon, polychlorinated biphenyl and metal contaminants in sediments in UK estuaries and coastal waters' Marine Pollution Bulletin 95: 469-479

Organisation for Economic Co-operation and Development (OECD) (2001), Extended Producer Responsibility: Guidance Manual for Governments

OSPAR Commission (OSPAR) (2010), Quality Status Report 2010 Status and trend in marine chemical pollution - Polychlorinated biphenyls

Roberts, D.A. (2012) 'Causes and ecological effects of re-suspended contaminated sediments (RCS) in marine environments’ Environment International 40: 230-243

Secretariat of the Stockholm Convention Clearing House (2016)

http://chm.pops.int/TheConvention/Compliance/tabid/61/Default.aspx (September 2016)

Stockholm Convention on persistent organic pollutants, opened for signature 23 May 2001, 2256 UNTS 000 (entered into force on 17 May 2004)

Stockholm Convention Bureau (SCB) (2016) 'Report of the meeting of the Bureau of the Conference of the Parties to the Stockholm Convention on Persistent Organic Pollutants, Geneva, Switzerland, 28-29 June 2016'

United Nations Environment Programme (UNEP) (2015a) 'Preliminary assessment of efforts made towards the elimination of polychlorinated biphenyls' 
United Nations Environment Programme (UNEP) (2015b), 'Report by the United Nations Environment Programme on progress in the implementation of the Polychlorinated Biphenyls Elimination Network', (23 February 2015), UNEP/POPS/COP.7/INF/10

United Nations Environment Programme (UNEP) (2007), 'Updated technical guidelines for the environmentally sound management of wastes consisting of, containing or contaminated with polychlorinated biphenyls (PCBs), polychlorinated terphenyls (PCTs) or polybrominated biphenyls (PBBs)

United Nations General Assembly (UNGA) (2012), The future we want, GA Res 66/288, UN GA $66^{\text {th }}$ sess, Agenda Item 19, UN Doc A/RES/66/288 (27 July 2012)

US Environmental Protection Agency (EPA) (2016a) https://www.epa.gov/superfund (27 October 2016)

US Environmental Protection Agency (EPA) (2016b) Hudson River PCB - Background and Site Information. http://www.epa.gov/hudson/background.htm

Verta M, Kiviranta H, Salo S, Malve O, Korhonen M, Verkasalo PK, Ruokojärvi P, Rossi E, Hanski A, Päätalo K, Vartiainen T. (2009) 'A decision framework for possible remediation of contaminated sediments in the River Kymijoki, Finland’ Environmental science and pollution research international 16(1): 95-105

Weber, R., Watson, A., Forter, M., and Oliaei, F. (2011) 'Review article: persistent organic pollutants and landfills - a review of past experiences and future challenges' Waste Management and Research 29(1): 107-121

Weber, R., Aliyeva, G., Vijen, J. (2013) 'The need for an integrated approach to the global challenge of POPs management' Environmental Science and Pollution Research 20: 1901-1906

Weber, R., Schlumpf, M., Nakand T. and Vijgen, J. (2015a) 'The need for better management and control of POPs stockpiles’ Environmental Science and Pollution Research 22: 14385-14390

Weber R, Hollert H, Kamphues J, Ballschmiter K, Blepp M, Herold C (2015b) ‘Analyse und Trendabschätzung der Belastung der Umwelt und von Lebensmitteln mit ausgewählten POPs und Erweiterung des Datenbestandes der POP-Dioxin-Datenbank des Bundes und der Länder mit dem Ziel pfadbezogener Ursachenaufklärung' R\&D Report for German EPA (UBA), FKZ 371265407/01

Xue J., Shi V.L., Zartarian V.G., Geller A.M. and Schultz B.D. (2016) Analysis of NHANES measured blood PCBs in the general US population and application of SHEDS model to identify key exposure factors. Journal of Exposure Science and Environmental Epidemiology 24: 615-621

Yoder, A.J. (2003) 'Lessons from Stockholm: Evaluating the Global Convention on Persistent Organic Pollutants’ Indiana Journal of Global Legal Studies 10(2): 113-156

Zhou Y, Asplund L, Yin G, Athanassiadis I, Wideqvist U, Bignert A, Qiu Y, Zhu Z, Zhao J, Bergman A (2016) 'Extensive organohalogen contamination in wildlife from a site in the Yangtze River Delta' Science of The Total Environment 554-555, 320-328 